Review

\title{
Increasing wind power penetration in autonomous power systems through no-flow operation of Pelton turbines
}

\author{
C.A. Platero ${ }^{\mathrm{a}, *}$, C. Nicolet $^{\mathrm{b}}$, J.A. Sánchez ${ }^{\mathrm{c}}$, B. Kawkabani ${ }^{\mathrm{d}}$ \\ ${ }^{a}$ Department of Electrical Engineering, ETSI Industriales, Universidad Politécnica de Madrid, C/José Gutiérrez Abascal, 2, 28006 Madrid, Spain \\ ${ }^{\mathrm{b}}$ Power Vision Engineering, Chemin des Champs-Courbes 1, CH-1024 Ecublens, Switzerland \\ ${ }^{\mathrm{c}}$ Department of Civil Engineering: Hydraulics and Energy, ETSICCP, Universidad Politécnica de Madrid, C/Profesor Aranguren $n^{\circ}$ 3, 28040 Madrid, Spain \\ d École Polytechnique Fédérale de Lausanne, EPFL STI STI-DEC GR-SCI-IEL, ELG 033 (Bâtiment ELG), Station 11, CH-1015 Lausanne, Switzerland
}

\section{A R T I C L E I N F O}

\section{Article history:}

Received 27 May 2013

Accepted 30 January 2014

Available online 12 March 2014

\section{Indexterms:}

Hydroelectric power generation

Power system dynamic stability

Frequency stability

Wind-power generation

\begin{abstract}
A B S T R A C T
The integration of wind power in power systems results in a reduction in greenhouse gas emissions. Thus, it has a positive environmental impact. However, the operation of these power systems becomes increasingly complex, owing mainly to random behaviour of the wind.

In the case of island power systems, this problem is even more difficult. The traditional solution is to use diesel generators as an alternative power supply. For a wind-only power supply, an energy storage system is required. If the topography of the island makes possible the use of pumped storage hydropower plants, this is, nowadays, the most suitable energy storage system.

This paper presents a novel method of Pelton turbine operation with no water flow, as a way to provide fast power injection in the case of an abrupt wind power decrease, or a wind-generator trip. This operation mode allows maximizing wind power penetration in a reliable and efficient way. This method has been validated by computer simulations, and will be tested during the commissioning of a combined wind-pumped storage power plant in an autonomous power system, on a small island.
\end{abstract}

(C) 2014 Elsevier Ltd. All rights reserved.

\section{Introduction}

In all power systems, frequency regulation should be carried out by the system operator, by balancing power generation and power consumption [1]. For this purpose, it is mandatory to have power plants that are easily adaptable to demand requirements. In the case of isolated power systems, frequency regulation is a very difficult problem owing to the small number of generators.

Moreover, in the case of some renewable power sources, such as wind power, it is not possible to supply the whole power demand in a reliable way, as a result of the intermittent behaviour of this type of energy source. Consequently, wind power penetration should be studied carefully [2] and limited, to prevent well-known network problems and incidents.

An additional problem in autonomous island power systems is the time response of the alternative power supply system, because in the case of a steep wind speed reduction, or a wind-generator trip, the power system frequency will drop quickly. To keep the

\footnotetext{
* Corresponding author. Tel.: +34 913363129; fax: +34 913363008.

E-mail addresses: carlosantonio.platero@upm.es, carlosantonio.platero@gmail. com (C.A. Platero).
}

power system in operation and to avoid a complete blackout, loadshedding systems must be installed [3]. When activated, they disconnect some consumers to balance power consumption and generation. As a result, the quality of the electricity supply service is reduced.

This paper presents a new strategy for operating hydropower plants. This strategy, applicable to plants equipped with Pelton turbines, consists of running the hydro generators synchronized to the grid, without water flowing through the Pelton turbines. Steep increase in the power demanded, abrupt wind power decrease or a wind-generator trip are detected upon system frequency drop, and lead to the injectors opening as quickly as possible, providing active power to the grid in the minimum possible time. In this way, power system frequency drop will be reduced, and consumer disconnections should be avoided. So it allows increasing the wind power penetration in a reliable way.

A Pelton unit power increase is limited by the hydraulics of the circuit; mainly the penstock. A negative water hammer occurs in the penstock during a fast opening of the injectors. Therefore, the limitation in the power injection ramp is imposed by the minimum allowable pressure in the penstock. If water pressure drops locally below vapour pressure, cavitation appears [4]. The development of 
a cavitation volume, resulting in a so-called water column separation, is followed by a collapse, leading to high pressure peaks that may load the hydraulic system structure severely, compromising system integrity.

Section 2 presents a brief overview of wind power integration, especially in small isolated power systems. Then, Section 3 presents the methodology, describing the low-pressure problem related to Pelton turbine steep power ramps, the principles of the proposed operating strategy for Pelton turbines and the computer model. Section 4 describes briefly a combined pumped storage-wind power plant where this new method of Pelton turbine operation will be tested. Its data have been used for the simulations. Section 5 analyses the software simulations of the proposed system. And, finally, Section 6 concludes with the main contributions of the proposed strategy.

\section{State-of-the-art wind power integration}

Large-scale integration of wind power generation is problematic, especially in small autonomous power systems.

To increase wind power penetration in such isolated power systems in a reliable way, it is important to have good wind-power forecasting [5] for the correct planning and operation of the power system [6].

However, even with a good wind-power forecasting system, it is essential to have an alternative power supply system for balancing generation and consumption, especially in low wind periods. In some cases, flywheels [7] or a battery energy storage system (BESS) [8] could be used as energy storage systems. There are other methods based on compressed air energy storage (CAES) [9], hydrogen fuel cells [10], or even ultra-capacitors [11]. Also, the combined use of several renewable energies and storage systems has been considered [12,13].

Nowadays, thanks to its larger capacity and its high efficiency, pumped storage hydropower plants are more suitable for this type of application, particularly in the case of high wind-power penetration [14].

A critical factor in island autonomous power systems is the time response of the alternative energy power supply system. Owing to the small number of generators, if a disturbance such as a windgenerator trip appears, the system frequency would fall quickly requiring a fast power injection to avoid load-shedding.

The time response of hydropower plants depends strongly on the hydraulic system layout and on the electro-mechanical equipment. There are several possibilities to improve the time response of pumped storage power plants, such as 3-machine-type [15] or variable speed operation [16].

The 3-machine-type combines an electrical machine, a pump and a turbine in the same shaft, with the same rotating direction. This configuration allows continuous power regulation in pump mode, and changing between pump and turbine operation modes in a shorter time.

In high-head hydro-pumped storage projects, and especially in the small power range, using two different hydraulic machines-Pelton turbines and high pressure pumps-coupled with two different electric machines, synchronous and asynchronous respectively, is a usual configuration [17]. This 4-machine-type allows the use of standard equipment, more easily available than tailor-made high-head pump-turbines. In addition, it is a more flexible arrangement than any other configuration, even the wellknown 3-machine type.

Other important factors to take into consideration in this type of power stations are operating policies [18] and economic analysis [19].

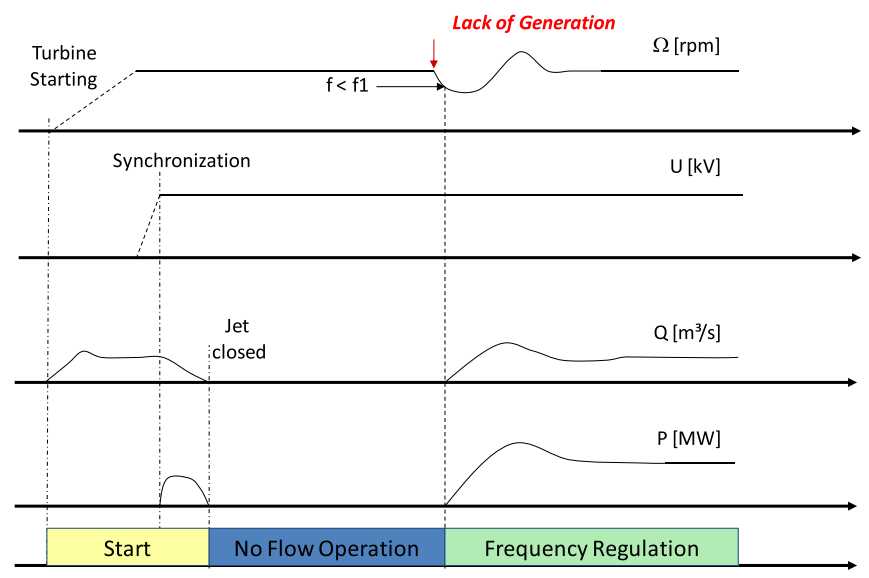

Fig. 1. Pelton turbine operation modes.

\section{Methodology}

\subsection{Problem of fast load increase in hydraulic turbines: the negative} water hammer

In all hydropower plants, a change in the plant operating point implies a flow change in the turbines and in the penstock. This flow change is achieved by a fast transient in the penstock. This transient produces oscillations, not only in the flow but also in the pressure. The actual pressures reached depend on the penstock characteristics, and their associated risk increases when the rated head increases.

Pelton turbines are used for high-head hydropower plants. Thus, hydraulic transients in these plants are critical and should be carefully addressed. The usual way to dampen transient pressure fluctuations is to increase the opening and closing time of the injectors. Thanks to the deflectors, these times are larger in Pelton turbines than in other hydraulic turbines.

The deflectors allow the deviation of the jet from the runner. They can be used during normal operation to achieve a fast reduction in the output power [20]. However, there is no device that performs a similar function when the output power must be increased quickly. The speed at which generated power rises depends on the opening time of the injectors, which is limited to prevent transients in the penstock. From the power response point of view, it should be as short as possible, but other considerations must be taken into account, to avoid cavitation problems.

Indeed, every increase in the flow is accompanied by a decrease in the pressure at the penstock: the negative water hammer. During transients, the pressure oscillations depend on the rate of flow change: a larger rate implies larger pressure oscillations. Therefore, a fast increase of flow could lead to negative transient pressures on some point of the penstock; penstocks may collapse under negative pressures. Also, low pressures could produce cavitation. Cavitation means the separation of the water column when the vapour pressure is greater than the pressure in the water conduit. The pressure peaks that appear when the vapour cavity collapses may reach amplitudes several times greater than the maximum amplitude of a direct water hammer. Therefore, for the penstock, the opening time of injectors should be as large as possible.

From the above description, it is obvious that the limiting element of the power generation ramp, in this type of hydropower plant, is the penstock.

\subsection{No-flow operation of Pelton turbine-driven generators}

In this paper, a new method is proposed to reduce the time needed to generate power in Pelton turbine-driven generators. This 
new method proposes synchronizing the Pelton turbine-driven generators with the power system as is normally done (Fig. 1. Start). First, switch on the turbine controller, which will open the injector so that the unit will accelerate to the rated speed. Next, switch on the automatic voltage regulator, so that the generator voltage will rise to its rated value. At this moment, the automatic synchronizer will put the generator online by closing the generator breaker.

After synchronizing the generators, the turbine jets will be closed (Fig. 1. No flow operation). At this stage, the machines will be rotating at the rated speed, and the synchronous generators will be operating as no-load motors. The power consumption in this operation mode will be very low (circa $2 \%$ of rated power), with only the power needed to compensate for the mechanical, iron and ventilation losses. If reactive power generation is required, this power consumption will be larger.

In this situation, the Pelton units are ready to inject power in minimum time because they are already synchronized. If the power system requires a fast power injection, the turbine controller should be switched to power frequency regulation mode (Fig. 1. Frequency Regulation). In this mode of operation, power ramps are limited by the maximum allowable rate of flow change in the penstock.

In order to change the control mode from no-flow operation to frequency regulation mode, a dedicated logic as the load-shedding should be used. In case the machine speed or the frequency would decrease below a certain value, the frequency regulation mode would be activated. The frequency or speed variation might also be used as a control signal. Such fast response can only be achieved with Pelton turbines, where no flow condition is obtained by closing the injectors. In Francis turbines, no flow conditions are commonly used to operate the units in condenser mode or to dispose of spinning reserve. However, these special operation modes require closing the main inlet valve, and dewatering the runner of the turbine using compressed air to reduce the hydro unit consumption and prevent from water excessive heating. The rewatering of the runner, main inlet valve and distributor opening procedure requires several seconds before active power can be provided. The associated time response is not compatible with the very fast reaction time required to limit frequency drop in isolated power networks.

Regarding Pelton turbines, when they are operated in spinning reserve, they are operated at minimum power that prevents from poor turbine and generator efficiency, and also to reduce turbine erosion. In case of condenser mode of operation, the hydro unit is also operated at no flow conditions, to provide voltage control services, but it is no meant to react to frequency deviations. In case of small autonomous islanded power system, where 4-machinetype arrangement is used, the spinning reserve operation leads to a reduction of the overall efficiency because additional pumping power is needed to compensate the additional turbine power, while it could be fairly adapted if variable speed pumps are selected. The no-flow operation described in this paper enables higher global system efficiency compared to classical spinning reserve, while the latter has the advantage of offering positive and negative power variations. In this power system, negative power variations are solved by increasing the pumping power consumption. If this is not possible, then wind power generation should be reduced.

\subsection{Computer model description}

By assuming uniform pressure and velocity distributions in the cross-section and neglecting the convective terms, the onedimensional momentum and continuity balances for an elementary pipe filled with water - length $\mathrm{d} x$, cross-section $A$ and wave speed $a$ (see Fig. 2) - lead to the following set of hyperbolic partial differential equations [21]:

$\left\{\begin{array}{l}\frac{\partial h}{\partial t}+\frac{a^{2}}{g A} \cdot \frac{\partial Q}{\partial x}=0 \\ \frac{\partial h}{\partial x}+\frac{1}{g A} \cdot \frac{\partial Q}{\partial t}+\frac{\lambda|Q|}{2 g D A^{2}} \cdot Q=0\end{array}\right.$

The system (1) is solved using the Finite Difference Method with a 1st-order centre scheme discretization in space, and a scheme of Lax for the discharge variable. This approach leads to a system of ordinary differential equations that can be represented as a Tshaped equivalent scheme [21-24], as presented in Ref. [25]. The resistance $(R)$, inductance $(L)$ and capacitance $(C)$ parameters of this equivalent scheme are given by:

$R=\frac{\lambda \cdot|\bar{Q}| \cdot \mathrm{d} x}{2 \cdot g \cdot D \cdot A^{2}} \quad L=\frac{\mathrm{d} x}{g \cdot A} \quad C=\frac{g \cdot A \cdot \mathrm{d} x}{a^{2}}$

where, $\lambda$ is the local loss coefficient. The hydraulic resistance $R$, the hydraulic inductance $L$, and the hydraulic capacitance $C$ correspond to energy losses, inertia and storage effects, respectively.

The model of a pipe of length $L$ is made of a series of $n_{\mathrm{b}}$ elements, based on the equivalent scheme of Fig. 2 . The system of equations relative to this model is set up using Kirchhoff laws. The model of the pipe, as well as the model of valve, surge tank, Francis turbine, etc., is implemented in the software SIMSEN, developed for the simulation of the dynamic behaviour of hydroelectric power plants [25-28]. The time-domain integration of the full system is achieved in SIMSEN by a Runge-Kutta 4th-order algorithm.

The modelling approach, based on equivalent schemes of hydraulic components, is extended to all the standard hydraulic components, such as valve, surge tanks, air vessels, cavitation development, Francis pump-turbines, Pelton turbines, Kaplan turbines, pump, etc. (see Ref. [16]).

The Pelton turbine is modelled using the turbine quasi-static characteristics, defined using the speed, discharge and torque factors, corresponding to $N_{11}, Q_{11}$, and $T_{11}$, respectively (Fig. 3). These factors are defined as follows:

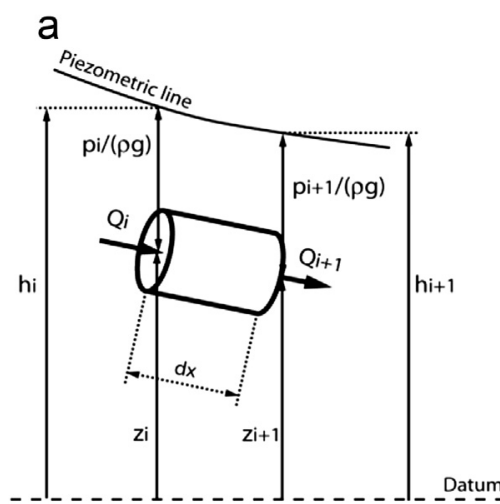

b

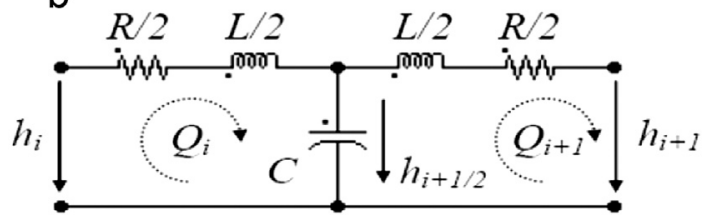

Fig. 2. a) Model of an elementary pipe, and b) the related equivalent scheme. 
$N_{11}=\frac{N \cdot D_{\mathrm{ref}}}{\sqrt{H}} ; \quad Q_{11}=\frac{Q}{D_{\mathrm{ref}}^{2} \cdot \sqrt{H}} ; \quad T_{11}=\frac{T}{D_{\mathrm{ref}}^{3} \cdot H}$

where $N$ is the rotational speed, $H$ is the net head and $D_{\text {ref }}$ is the reference diameter of the turbine. Fig. 4 presents an example of a single-injector Pelton turbine characteristic with the injector discharge characteristic, where the discharge factor is represented as a function of the injector opening $Q_{11}=Q_{11}\left(y_{\text {inj }}\right)$ (see Fig. 3, left), and the torque characteristic, where the torque factor is represented as a function of the speed factor and of the injector opening $T_{11}=T_{11}\left(y_{\text {inj }}, N_{11}\right)$ (see Fig. 3, right).

As energy transfer in Pelton turbines is achieved at a constant pressure, the Pelton turbine model in Fig. 4 can be divided into two parts: one hydraulic; and one mechanical. From the hydraulic point of view, the Pelton turbine can be modelled as an equivalent valve, taking into account the needle position of each injector. Thus, the equivalent scheme of the Pelton turbine is a variable resistance, as presented in Fig. 5, where the resistance related to each injector can be expressed as follows:

$R_{\mathrm{t}}=\frac{\left|Q_{\text {inj }}\right|}{Q_{11}^{2}\left(y_{\text {inj }}\right) \cdot D_{\text {ref }}^{4}}$

Then, the torque contribution of each injector is deduced from the torque characteristic by knowing the injector opening, the net head and the rotational speed. The deflectors have not been considered in this study. Then, the rotational speed of the unit is computed using the rotating momentum equation as follows:

$J_{\text {tot }} \frac{\mathrm{d} \omega}{\mathrm{d} t}=T-T_{\text {elect }}$

where $J_{\text {tot }}$ is the total inertia of the rotating masses, $\omega$ is the pulsation, $T$ is the torque of the turbine and $T_{\text {elect }}$ is the electromagnetic torque of the generator.

\section{Combined wind and pumped-storage power plant case study: El Hierro}

\subsection{Power system description}

The power plant of interest, comprising a wind farm and a pumped storage power plant with a 4-machine-type arrangement, is under construction on the island of El Hierro, in the Canary Islands archipelago, Spain. This island has a population of 10,500 people and a surface area of $275 \mathrm{~km}^{2}$. The maximum historic peak

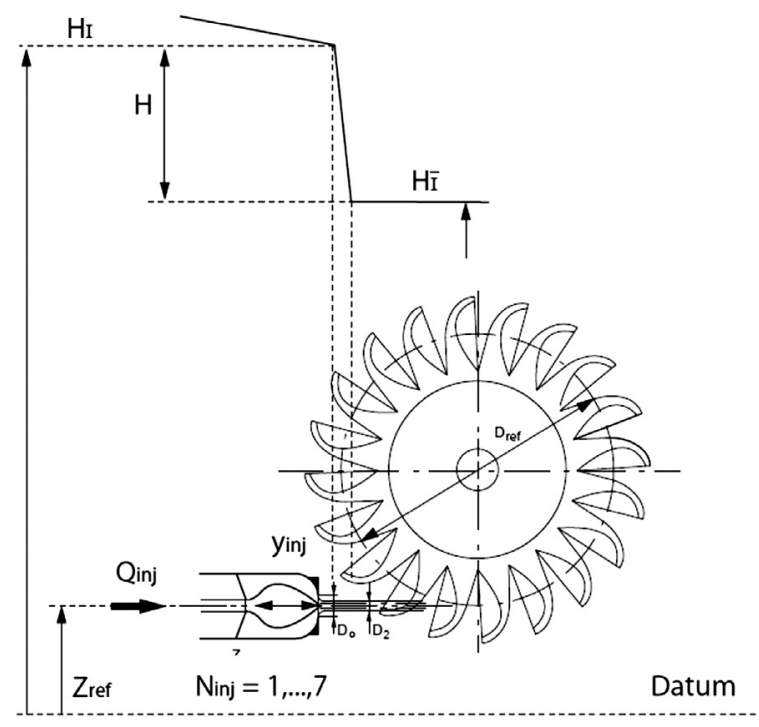

Fig. 4. Model of a Pelton turbine.

demand of 7.8 MW was reached on 12th August, 2010, as a result of a heat wave [29], while the maximum peak demand in normal operation conditions is around $7 \mathrm{MW}$. On the other hand, the valley hour consumption is circa $4 \mathrm{MW}$ [30].

The current power station has nine units and a total installed power of 11.3 MW. The units are four-stroke diesel-engine-driven generators. The biggest diesel unit has a rated power of $2000 \mathrm{~kW}$. The wind conditions in this island are auspicious for wind power generation, with average wind speed of $9.5 \mathrm{~m} / \mathrm{s}$. This wind farm is expected to operate circa 3500 full power equivalent hours per year. The island's volcanic origin makes it possible to build an upper and a lower reservoir, with a useful capacity of $380,000 \mathrm{~m}^{3}$ and $150,000 \mathrm{~m}^{3}$ respectively, for pumped storage integration. In Fig. 7, a layout based on the information of Ref. [31] is shown.

A simplified single line diagram of the El Hierro power system, including the new wind power generation, as well as the pumped storage power plant, is represented in Fig. 8. This new power plant comprises 4 Pelton units with a total rated power of 11.32 MW, 5 wind generators with a maximum power of $11.5 \mathrm{MW}$ and a pumping station with a maximum power of $6 \mathrm{MW}$. The Pelton turbines and pumps have independent penstocks. Detailed data on this power plant can be found in Tables $2-5$ in the Appendix.
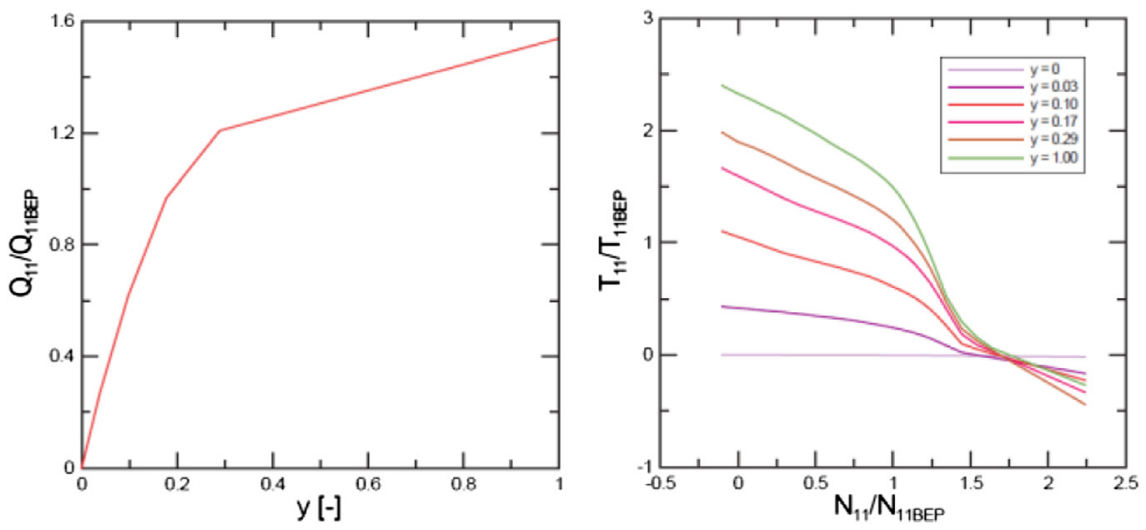

Fig. 3. Example of Pelton turbine characteristic curves with injector discharge characteristic curve (left), and torque characteristic curve (right). 


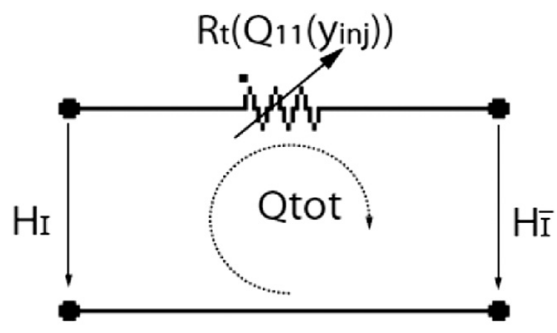

Fig. 5. Electrical equivalent scheme of a Pelton turbine.
In this power system, voltage is regulated by the connected synchronous generators through a conventional brushless excitation system and an Automatic Voltage Regulator (AVR).

El Hierro island is a UNESCO Biosphere reserve, and aims to become a $100 \%$ carbon-free island [32]. Among the projects considered is this combined wind and pumped storage power plant, which aspires to provide all electrical energy needs of this island from wind power. For this purpose, it is necessary to integrate an $11.5 \mathrm{MW}$ wind farm in a power system with a minimum power consumption of $4 \mathrm{MW}$. So, the wind farm could generate, in some cases, three times the power consumption. Therefore, building an energy storage system is unavoidable. There are other

Wind Turbine Driven Generator

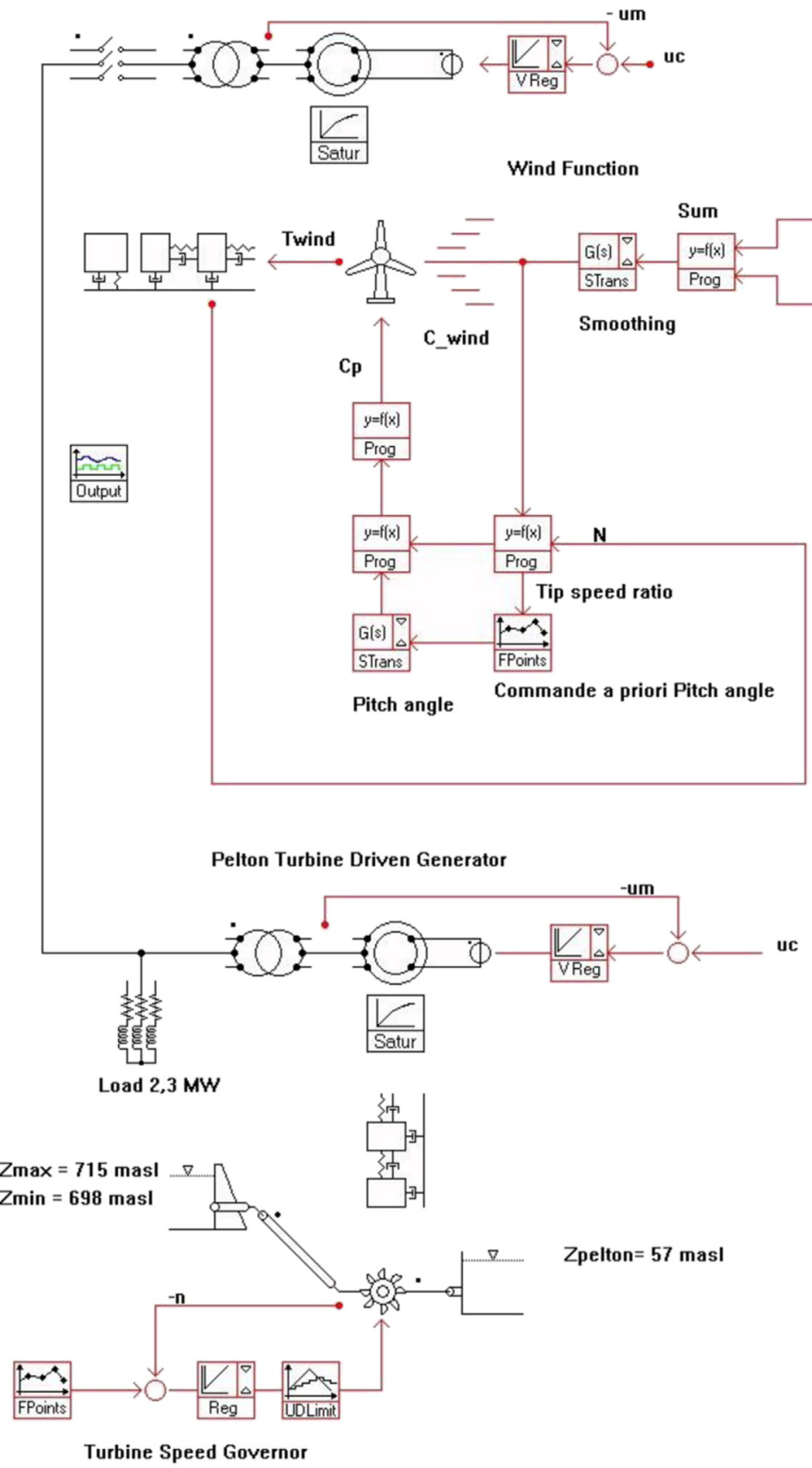

Fig. 6. El Hierro combined wind and pumped-storage hydropower plant simplified simulation model, as implemented in SIMSEN software for wind-generator trip simulation. 


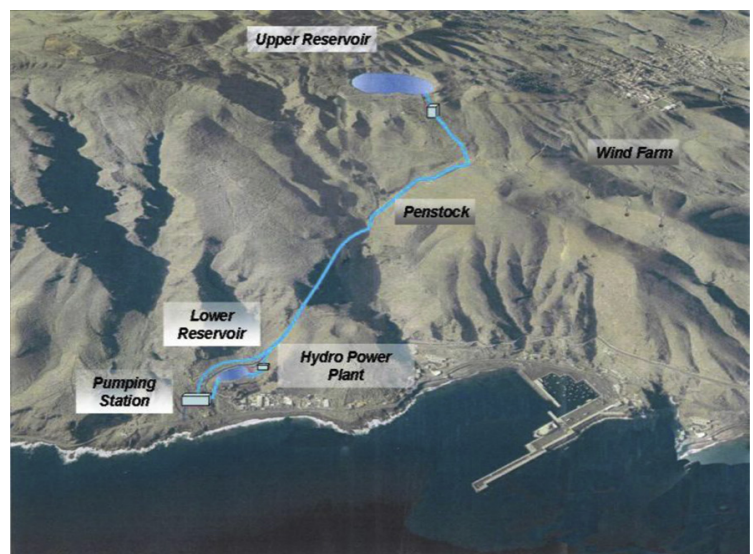

Fig. 7. El Hierro combined wind and pumped-storage hydropower plant layout.

remarkable projects for an island autonomous power system, as presented in Ref. [17], with similar characteristics.

For the project presented here, with such high wind-power penetration, using a pumped-storage power plant is mandatory. This power plant should be able to regulate the frequency fluctuations of the power system, producing the power demanded by the consumers, or consuming the excess power of the wind farm, in steady-state and in transients.

Thus, when there is not enough wind power, the power plant should operate in turbine mode, generating power. If there were an excess in the available wind power, the power plant should operate in pump mode with continuous power regulation, in order to achieve a constant power system frequency.

Additionally, the power plant must be prepared to change as quickly as possible from pump mode to turbine mode, or vice versa, because it could be the only power station in the power system with power-regulating capability.

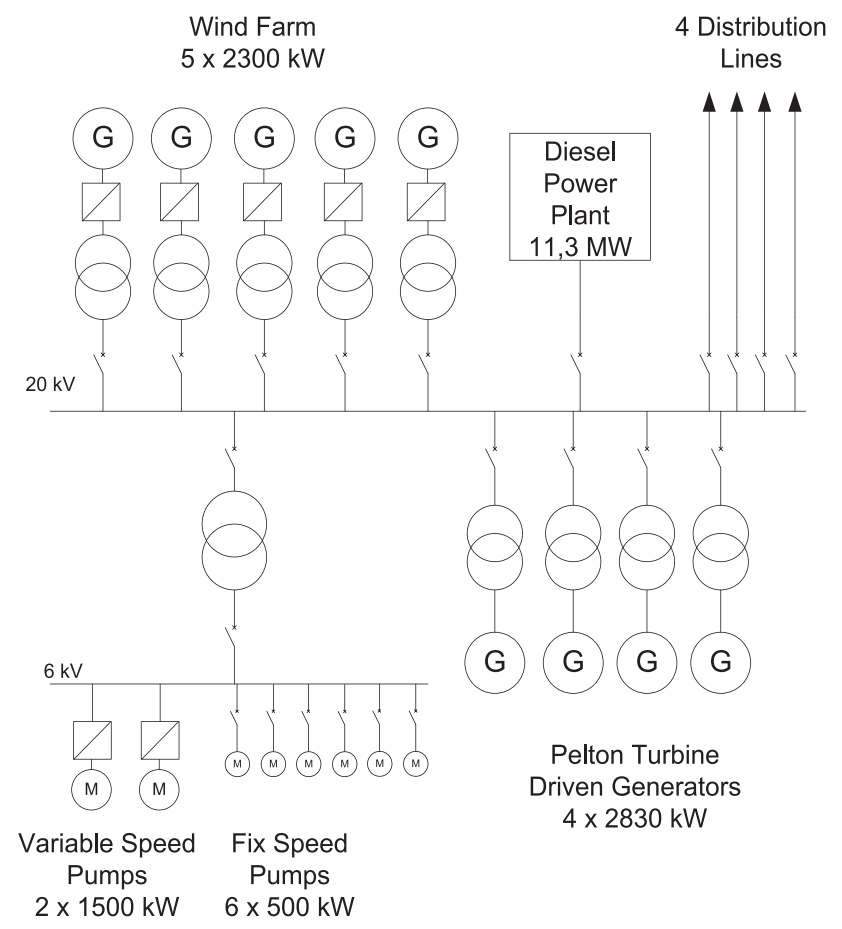

Fig. 8. El Hierro power system, simplified single line diagram.

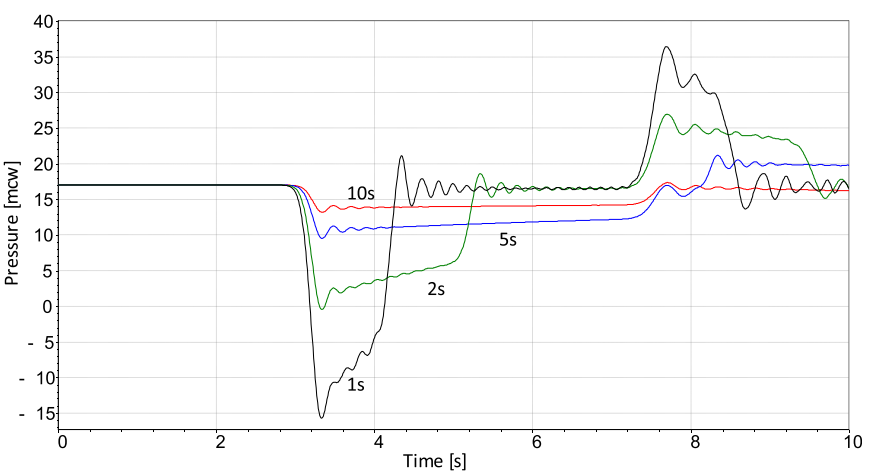

Fig. 9. Penstock pressure evolution (upper zone) during a full injector opening for $1 \mathrm{~s}$, $2 \mathrm{~s}, 5 \mathrm{~s}$ and $10 \mathrm{~s}$.

To summarize, the main requirements for this project are maintaining the frequency within the power quality limits according to regulations [33], and surviving the trip of the biggest generator without load-shedding. The load shedding frequency relay is set to $48.5 \mathrm{~Hz} / 0.1 \mathrm{~s}$. This requires a power plant with a fastinjecting power capability.

\subsection{Power system model}

Basically, the power system is composed of two generation units: wind generators; and Pelton turbine-driven generators. There is also an electrical load representing the consumers, and a circuit breaker to simulate a wind-generator trip (Fig. 6). The diesel power plant is not considered in the computer model.

The model of the hydropower plant takes into account the upstream reservoir with constant water level, the penstock, and the Pelton units, modelled as one equivalent turbine and one generator. The turbine speed governor is modelled as a proportional-integral-derivative controller PID, and includes limiters and rate limiters. The governor has two sets of parameters: one valid for small frequency deviation, $\pm 1 \%$ of the rated frequency; and another set of parameters valid for larger deviations.

\section{Analysis of simulation results}

Initially, simulations were carried out to determine the shortest opening time of the injectors that avoids cavitation problems. Once this opening time was determined, other disturbances in the power system were simulated to verify the no-flow operation of the Pelton turbines, especially in the case of wind-generation loss.

\subsection{Shortest opening time of the injectors}

These simulations study the full linear opening of the injectors for different opening times. Fig. 9 shows the pressure at the top of the penstock for the different injector-opening times $(1 \mathrm{~s}, 2 \mathrm{~s}, 5 \mathrm{~s}$ and $10 \mathrm{~s}$ ). As can be seen, a negative pressure could appear if the opening time is too short (lower than $2 \mathrm{~s}$ ). These negative pressures imply cavitation problems. On the other hand, Fig. 10 shows the pressure at the inlet of the turbine, the end of the penstock. It can be clearly observed that the pressure oscillations are larger when the opening time is shorter. It should be noted that, in these simulations, $17 \mathrm{~m}$ water level in the upper reservoir is considered.

Figs. 11 and 12 show the time evolution of the water hammer along the pipe $(2.8,17.6,36.1,54.6,73.1,91.7$ and $100 \%)$ for injector opening times of $1 \mathrm{~s}$ and $10 \mathrm{~s}$, respectively. 


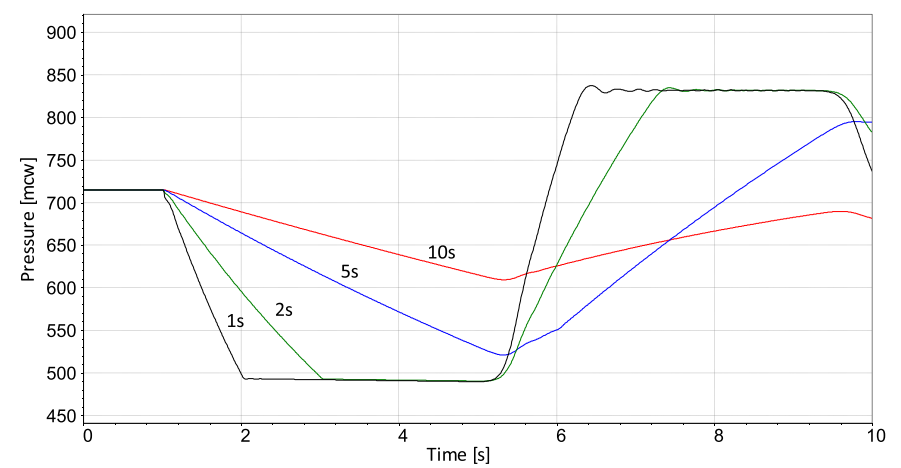

Fig. 10. Penstock pressure evolution (turbine inlet) during a full injector opening for $1 \mathrm{~s}, 2 \mathrm{~s}, 5 \mathrm{~s}$ and $10 \mathrm{~s}$.

The minimum total opening time of the injectors has been set to $10 \mathrm{~s}$ because it is the shortest time that avoids hydraulic problems, even if the upper reservoir is at its minimum operating level.

\subsection{Wind-generator trip}

From the power system point of view, the most severe scenario is the tripping of one wind generator at full load, during the minimum load period. In the simulations, the wind-generator trip represents a $100 \%$ loss of generation in the period of minimum load.

During the initial conditions, the frequency is $50 \mathrm{~Hz}$, while the Pelton turbine-driven generator is operating at no flow $(\approx 0 \mathrm{MW})$, so all the loads are supplied by the wind generator $(\approx 2.3 \mathrm{MW})$.

The wind-generator trip is simulated by opening its breaker. Subsequently, the 4 hydro generators increase their generated power to maintain the system frequency. In this case, the fastest power injection to the system is mandatory to avoid the disconnection of consumers.

However, owing to the hydraulic limitations, the opening time of the injectors is limited to $10 \mathrm{~s}$. So, it is necessary to add additional inertia to the generators, in order to keep the frequency above the load-shedding threshold.

Simulations have been performed to determine the minimum inertia of the generators, in order to not fall below certain limits of frequency, and to set the turbine speed governor parameters.

The minimum frequency reached depends on the inertia of the hydro generators (see Table 1), and should be coordinated with the load-shedding relay installed on the island power system. In Fig. 13 the frequency oscillations resulting from the wind-generator trip, for different hydro generator inertia, are shown.

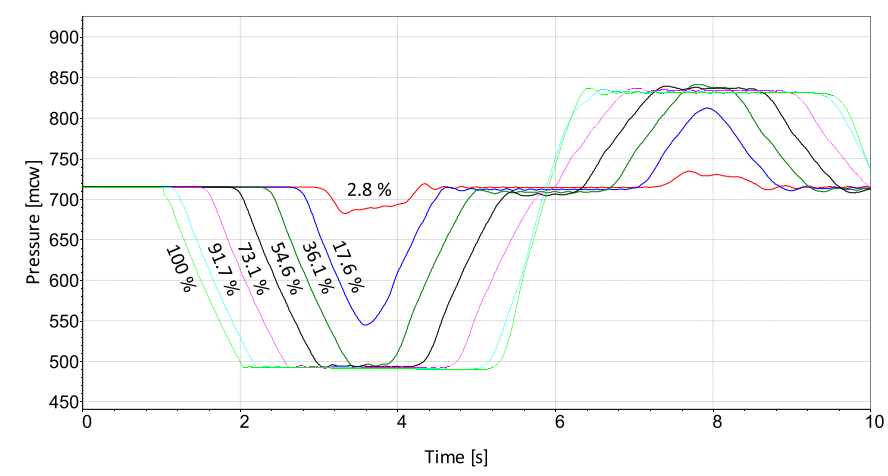

Fig. 11. Piezometric head evolution during a full injector opening in $1 \mathrm{~s}$ along the penstock.

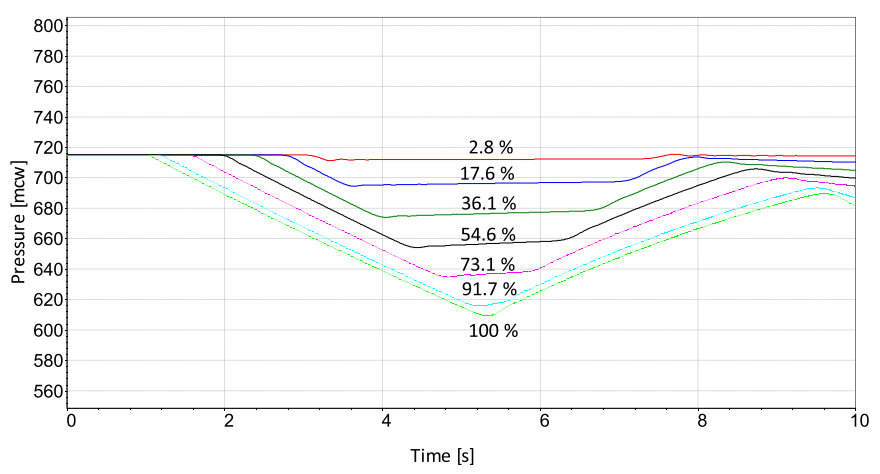

Fig. 12. Piezometric head evolution during a full injector opening in $10 \mathrm{~s}$ along the penstock.

In order to get a minimum frequency of $48.8 \mathrm{~Hz}$, an inertia of $6 \mathrm{~s}$ is required. Fig. 14 shows the complete frequency evolution after a generator trip, highlighting the interaction between the hydraulic circuit dynamics and the power system frequency, as the period of the frequency oscillation corresponds to the penstock water hammer period $T=4 L / a=4.3 \mathrm{~s}$.

Fig. 15 shows the evolution of the main turbine variables after a generator trip. Although the net head drops slightly (0.1 pu) just after the injectors open, the flow increases from zero to a positive value. So, the mechanical power supplied by the turbines also increases from zero to a positive value.

\section{Conclusions}

A novel operation mode of generators driven by Pelton turbines has been presented in this paper. This method has been validated by computer simulations.

The purpose of this no-flow operation mode is to reduce the time needed to supply power using a hydropower plant. This time reduction is of paramount importance in the case of lack of wind, or a wind-generator trip, in an isolated power system. In this way, wind penetration can be increased, supplying power in a reliable and efficient way. With this aim, it must be taken into account that an injector's opening time has a minimum value limited by the hydraulic characteristics of the penstock. In order to overcome the effect of this limitation, an increase in hydro generator units' inertia is proposed. In the case study, the minimum inertia that avoids load-shedding is quantified.

According to the simulations performed, a $100 \%$ wind power penetration could be reached.

This operation mode will be tested in the electrical grid of a small island, called El Hierro, in the Canary archipelago, where a combined wind and pumped storage power plant is under construction.

To summarize, the no-flow operation main advantages are:

- fastest power injection in the case of requiring the alternative power system (penstock design limit may be overcome by increasing hydro generators' inertia).

Table 1

Minimum frequency reached after a wind-generator trip.

\begin{tabular}{ll}
\hline Hydro generator inertia [s] & Minimum frequency $[\mathrm{Hz}]$ \\
\hline 6 & 48.8 \\
4.5 & 48.5 \\
3 & 47.75 \\
\hline
\end{tabular}




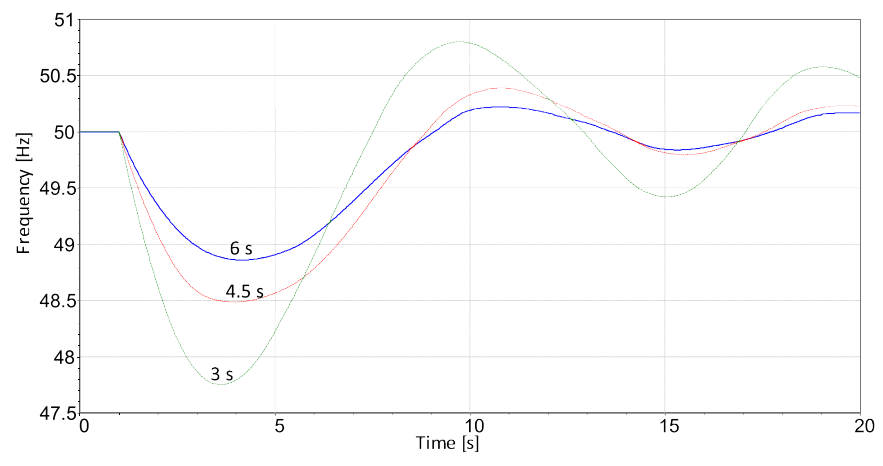

Fig. 13. Frequency evolution during a wind-generator trip, for different values of the hydro generator inertia coefficient $H(6 \mathrm{~s}, 4.5 \mathrm{~s}$ and $3 \mathrm{~s})$.

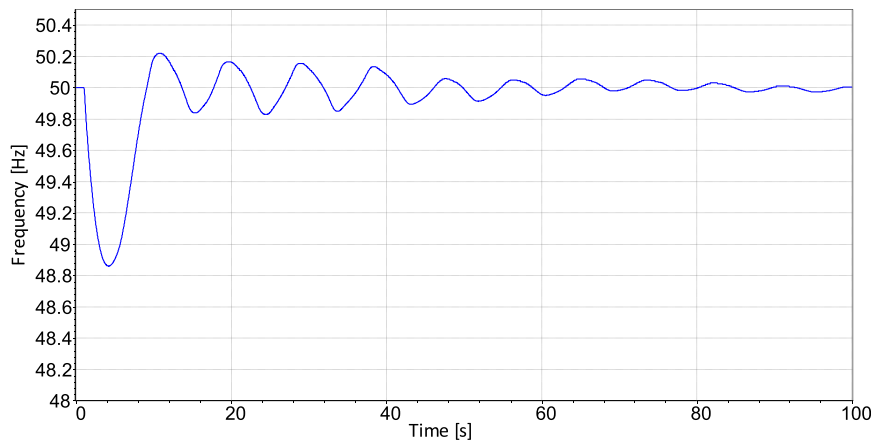

Fig. 14. Frequency evolution during a wind-generator trip, for a $6 \mathrm{~s}$ value of the hydro generator inertia coefficient, $H$, and 4 Pelton generators online.

- maximum wind-power penetration in the power system. However, additional inertia could be needed to maintain the frequency while the turbine jet reaches the required flow.

- standard equipment with no special design.

Other advantages related to the increase in the number of generators in operation are:

- the hydropower plant could contribute to the voltage control of the grid, providing reactive power if required.

- increase in the reactive current injection during faults.

- improvement of the power system transient stability.

In addition to the innovative design, this type of power plant will allow the more efficient harnessing of wind power.

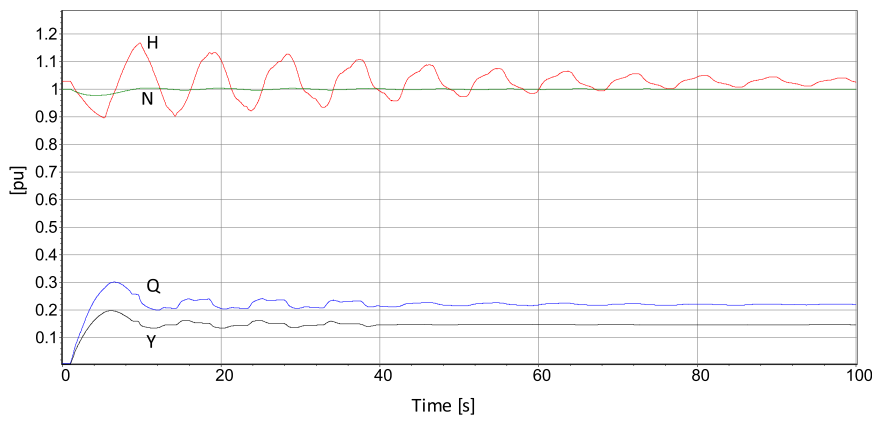

Fig. 15. Evolution of turbine inlet pressure $H$, flow $Q$, valve opening $Y$ and speed $N$, during a wind-generator trip, for a hydro generator inertia coefficient, $H$, of $6 \mathrm{~s}$ and 4 Pelton generators online.

\section{Acknowledgements}

The authors wish to thank the technical support of J.R. Diago, M. Alvarez and C. Romero, of ENDESA Generación SA. Also they wish to acknowledge the support of the Intellectual Property Department of ENDESA [34], as well as Fundación Caja Madrid for its financial support.

\section{Appendix}

Table 2

Penstock ratings.

\begin{tabular}{ll}
\hline Penstock & 1 \\
\hline Diameter & $1 \mathrm{~m}$ \\
Length & $2577 \mathrm{~m}$ \\
Darcy-Weisbach friction loss coefficient & 0.015 \\
Wave speed & $1193 \mathrm{~m} / \mathrm{s}$ \\
Number of elements for simulation & 54 \\
\hline
\end{tabular}

Table 3

Pelton turbine ratings

\begin{tabular}{ll}
\hline Pelton turbines & 4 \\
\hline Rated power & $2830 \mathrm{~kW}$ \\
Rated flow & $0.5 \mathrm{~m}^{3} / \mathrm{s}$ \\
Gross head & $670 \mathrm{~m}$ \\
Net head & $651 \mathrm{~m}$ \\
Rated speed & $1000 \mathrm{rpm}$ \\
Number of jets per runner & 1 \\
Type & Horizontal \\
\hline
\end{tabular}

Table 4

Hydro generator ratings

\begin{tabular}{ll}
\hline Hydro synchronous generators & 4 \\
\hline Rated apparent power & $3300 \mathrm{kVA}$ \\
Rated Power Factor & 0.8 \\
Rated voltage $( \pm 5.0 \%)$ & $6 \mathrm{kV}$ \\
Frequency & $50 \mathrm{~Hz}$ \\
Pairs of poles & 3 \\
Rated speed & $1000 \mathrm{rpm}$ \\
Direct-axis synchronous reactance (unsat) Xd & $1.901 \mathrm{pu}$ \\
Quadrature-axis synchronous reactance Xq & $1.049 \mathrm{pu}$ \\
Direct-axis subtransient reactance (unsat) $\mathrm{X}^{\prime} \mathrm{d}$ & $0.183 \mathrm{pu}$ \\
Direct-axis subtransient reactance (unsat) $\mathrm{X}^{\prime \prime} \mathrm{d}$ & $0.120 \mathrm{pu}$ \\
Leakage reactance (stator) Xl & $0.125 \mathrm{pu}$ \\
Direct-axis transient open-circuit time constant $\mathrm{T}^{\prime} \mathrm{do}$ & $4.354 \mathrm{~s}$ \\
Direct-axis transient short-circuit time $\mathrm{T}^{\prime} \mathrm{d}$ & $41 \mathrm{~ms}$ \\
Direct-axis subtransient short-circuit time $\mathrm{T}^{\prime \prime} \mathrm{d}$ & $17 \mathrm{~ms}$ \\
Stator resistance per phase $\left(95{ }^{\circ} \mathrm{C}\right)$ & $0.002 \mathrm{pu}$ \\
Inertia & Various s \\
\hline
\end{tabular}

Table 5

Pumps ratings

\begin{tabular}{llll}
\hline Pumps & 6 & 2 & \\
\hline Rated power & 500 & 1500 & $\mathrm{~kW}$ \\
Rated flow & 210 & 640 & $\mathrm{~m}^{3} / \mathrm{h}$ \\
Gross head & 690 & 690 & $\mathrm{~m}$ \\
Maximum efficiency & 78.1 & 81.9 & {$[\%]$} \\
Rated speed & 2965 & 2973 & $\mathrm{rpm}$ \\
Motor & Asynchronous & Asynchronous variable speed & \\
& fixed speed & & \\
Type & High pressure & High pressure horizontal & \\
& horizontal & & \\
\hline
\end{tabular}




\section{References}

[1] Kundur P. Power system stability and control. Palo-Alto, California: McGrawHill; 1994.

[2] Steinke F, Wolfrum P, Hoffmann C. Grid vs. storage in a 100\% renewable Europe. Renew Energy 2013;50:826-32.

[3] De Vos K, Petoussis A, Driesen J, Belmans R. Revision of reserve requirements following wind power integration in island power systems. Renew Energy 2013;50:268-79.

[4] Bergant A, Simpson AR, Tisseling AS. Water hammer with column separation: a historical review. J Fluids Struct 2006:22(2):135-71.

[5] Blonbou R. Very short-term wind power forecasting with neural networks and adaptive Bayesian learning. Renew Energy 2011;36:1118-24.

[6] Xu M, Zhuan X. Optimal planning for wind power capacity in an electric power system. Renew Energy 2013;53:280-6.

[7] Cimuca G, Breban S, Radulescu MM, Saudemont C, Robyns B. Design and control strategies of an induction-machine-based flywheel energy storage system associated to a variable-speed wind generator. IEEE Trans Energy Convers 2007;25:526-34.

[8] Khalid M, Savkin AV. An optimal operation of wind energy storage system for frequency control based on model predictive control. Renew Energy 2012;48: $127-32$.

[9] Abbaspour M, Satkin M, Mohammadi-Ivatloo B, Hoseinzadeh Lotfi F, Noorollahi Y. Optimal operation scheduling of wind power integrated with compressed air energy storage (CAES). Renew Energy 2013;51:53-9.

[10] Valdés R, Lucio JH, Rodríguez LR. Operational simulation of wind power plants for electrolytic hydrogen production connected to a distributed electricity generation grid. Renew Energy 2013;53:249-57.

[11] Muyeen SM, Takahashi R, Murata T, Tamura J. Integration of an energy capacitor system with a variable-speed wind generator. IEEE Trans Energy Convers 2006;24:740-9.

[12] Ashourian MH, Cherati SM, Mohd Zin AA, Niknam N, Mokhtar AS, Anwari M. Optimal green energy management for island resorts in Malaysia. Renew Energy 2013;51:36-45.

[13] Hedegaard K, Meibom P. Wind power impacts and electricity storage - a time scale perspective. Renew Energy 2012;37:318-24.

[14] Katsaprakakisa D Al, Christakis DG, Zervosb A, Papantonis D, Voutsinas S. Pumped storage systems introduction in isolated power production systems. Renew Energy 2008;33:467-90.

[15] Nicolet C, Vaillant Y, Kawkabani B, Allenbach P, Simond J-J, Avellan F. Pumped storage units to stabilize mixed islanded power network: a transient analysis. In: Proceedings of HYDRO 2008, October 6-9, 2008, in Ljubljana, Slovenia. Paper 16.1.

[16] Nicolet C, Pannatier Y, Kawkabani B, Schwery A, Avellan F, Simond J-J. Benefits of variable speed pumped storage units in mixed islanded power network during transient operation. In: Proceedings of HYDRO 2009, October 26-28, 2009, in Lyon, France. Paper 23.3.
[17] Papaefthymiou SV, Karamanou EG, Papathanassiou SA, Papadopoulos MP. Wind-hydro-pumped storage station leading to high RES penetration in the autonomous island system of Ikaria. IEEE Trans Sustain Energy 2010;1:163-72.

[18] Papaefthimiou S, Karamanou E, Papathanassiou S, Papadopoulos M. Operating policies for wind-pumped storage hybrid power stations in island grids. IET Renew Power Gener 2009;3(3):293-307.

[19] Kapsalia M, Anagnostopoulosb JS, Kaldellis JK. Wind powered pumped-hydro storage systems for remote islands: a complete sensitivity analysis based on economic perspectives. Appl Energy 2012;99:430-44.

[20] Johnson RM, Chow JH, Dillon MV. Pelton turbine deflector overspeed control for a small power system. IEEE Trans Power Syst 2004;19(2):1032-7.

[21] Wylie EB, Streeter VL. Fluid transients in systems. Englewood Cliffs, N.J: Prentice Hall; 1993.

[22] Jaeger RC. Fluid transients in hydro-electric engineering practice. .Glasgow: Blackie; 1977.

[23] Paynter HM. Surge and water hammer problems. Trans ASCE 1953;146:9621009.

[24] Souza Jr OH, Barbieri N, Santos AHM. Study of hydraulic transients in hydropower plants through simulation of nonlinear model of penstock and hydraulic turbine model. IEEE Trans Power Syst 1999;14(4):1269-72.

[25] Nicolet C. Hydroacoustic modelling and numerical simulation of unsteady operation of hydroelectric systems. Thesis EPFL $n^{\circ} 3751$, http://library.epfl.ch/ theses/?nr=3751; 2007.

[26] Nicolet C, Greiveldinger B, Hérou J-J, Kawkabani B, Allenbach P, Simond J-J, et al. High order modeling of hydraulic power plant in islanded power network. IEEE Trans Power Syst 2007;22(4):1870-81.

[27] Pannatier Y, Kawkabani B, Sari G, Simond J-J. Stability studies of a mixed islanded power network with varspeed units using simplified models of the converters. Energy Conversion Congress and Exposition (ECCE) IEEE; 2010: 2552-7.

[28] Padoan Jr AC, Kawkabani B, Schwery A, Ramirez C, Nicolet C, Simond JJ, et al. Dynamical behavior comparison between variable speed and synchronous machines with PSS. IEEE Trans Power Syst 2010;25:1555-65.

[29] Red Eléctrica de España S.A. Balance del sistema eléctrico canario 2010. http:// www.ree.es/sala_prensa/web/inc/fichero.aspx?ruta=especiales/ archivos\&fichero=pjbwxf5un6ka.pdf.

[30] Red Eléctrica de España S.A. Power demand tracking in real time. http://www. ree.es/seie/canarias/curvas_demanda.asp.

[31] Ministerio de Agricultura Alimentación y Medio Ambiente. El Hierro, en el camino hacia la autosuficienca energética. www.magrama.gob.es.

[32] Iglesias G, Carballo R. Wave resource in El Hierro - an island towards energy self-sufficiency. Renew Energy 2011;36:689-98.

[33] European Standard EN 50160:2007. Voltage characteristics of electricity supplied by public distribution networks.

[34] Platero CA, Blazquez F, Rodríguez J, Ballesteros JC, Veganzones C, Martínez S, et al. Control method and system for hydraulic wind farms with pumped accumulation. International Patent, PCT/ES2010/070133. March 9, 2010. 